\title{
CHEMICAL LOOPING COMBUSTION RELATED PROCESSES USING SOLID OXYGEN CARRIERS OXIDIZED IN $\mathrm{CO}_{2}$ ATMOSPHERE
}

\begin{abstract}
Chemical-looping combustion (CLC) is an attractive process in $\mathrm{CO}_{2}$ capture, especially when solid oxygen carriers are used in it. The main requirements for oxygen-transporting materials include appropriate oxidation (in air) and reduction (in the presence of fuel) ability. In the paper a conceptual proposition for CLC-related processes with the application of solid oxygen carriers oxidized in both air and $\mathrm{CO}_{2}$ atmosphere has been presented. The possibility of the "looping" process on the same carriers using both $\mathrm{CO}_{2}$ and air atmosphere as an oxidizing agent allows us to enrich the concept of CLC and related processes by proposing a cyclic recirculation of the produced $\mathrm{CO}_{2}$ back to the installation. The oxidizing of solid oxygen carrier in a $\mathrm{CO}_{2}$ atmosphere is accompanied by $\mathrm{CO}$ emission from the plant. This toxic gas could be transformed into a useful product in any chemical process. It is possible to combine the looping processes with manufacturing of any appropriate morphological form of carbon in the cyclic $\mathrm{CO}$ disproportionation process. The combined process could lead to a lower $\mathrm{CO}_{2}$ emissions to the environment. $\mathrm{SrTiO}_{3}$ doped by $\mathrm{Cr}$ (STO:Cr) and a mixture of $\mathrm{TiO}_{2}$ - and Ni-based compounds $\left(\mathrm{TiO}_{2}-\mathrm{Ni}\right)$ were investigated as oxygen transporting materials. The experiment methodology based on thermogravimetric, diffraction and spectroscopic studies was shown. Thermogravimetric (TGA) and Powder Diffraction (XRD) measurements were provided in-situ during a few cycles in a reducing $\left(\mathrm{Ar}+3 \% \mathrm{H}_{2}\right)$ and oxidizing environment. Moreover, the STO:Cr powders were characterized ex-situ by the X-ray Photoelectron Spectroscopy (XPS) method. It was found that in tested conditions the cyclic process of the investigated powders' oxidation and reduction is possible. Satisfactory results considering the oxygen transport capacity was obtained for the $\mathrm{TiO}_{2}-\mathrm{Ni}$ sample.
\end{abstract}

Keywords: $\mathrm{CO}_{2}$, chemical looping combustion, chemical looping dry reforming, chemical looping gasification, solid oxygen carrier, $\mathrm{CO}_{2}$ decomposition, $\mathrm{CO}$ disproportionation

\section{Introduction}

The Kyoto Protocol [1], which entered into force in 2005, obligates the countries that have ratified it to reduce $\mathrm{CO}_{2}$ emissions to the atmosphere. The necessity of reducing the energy inputs in industrial processes that has been imposed by the Protocol is one of the main reasons behind searches for new technologies aimed at reducing emissions of the gas. Chemical-looping combustion (CLC) and chemical looping gasification (CLG) are

\footnotetext{
${ }^{1}$ Łukasiewicz Research Network, Refractory Materials Division, Institute of Ceramics and Building Materials, ul. Toszecka 99, 44-100 Gliwice, Poland

${ }^{2}$ The "Edith Stein School with Character" Foundation, ul. Bałtycka 8, 44-100 Gliwice, Poland

${ }^{3}$ A. Chełkowski Institute of Physics, University of Silesia, ul. 75. Pułku Piechoty 1, 41-500 Chorzów, Poland

${ }^{4}$ Silesian Centre for Education and Interdisciplinary Research, ul. 75. Pułku Piechoty 1A, 41-500 Chorzów, Poland

*Corresponding author: psiuk.bronislaw@gmail.com
} 
attractive processes which facilitate $\mathrm{CO}_{2}$ capture. In this technology solid oxygen carriers are used - then the combustion air and fuel have no direct contact and, therefore, are never mixed. One of the main requirements for oxygen-transporting materials is an appropriate oxidation (in air) and reduction (in the presence of fuel) ability [2-4]. In the CLC solution a pure $\mathrm{CO}_{2}$ stream leaves the system [5-7]. There are a lot of possibilities for gas sequestration like: storage in used oil and gas fields or deep coal beds, storage in aquifers, chemisorption processes and formation of carbonates, etc. [8-16]. However, scientific works also show possibilities of decreasing a $\mathrm{CO}_{2}$ amount in the atmosphere by dissociating the gas molecules e.g. [17-20]. Recently a concept of chemical looping dry reforming (CLDR) has been proposed [21]. The CLDR process is similar to CLC, but in the former the air is replaced only by $\mathrm{CO}_{2}$. The new proposition requires oxygen carriers which are capable of oxidizing in a $\mathrm{CO}_{2}$ atmosphere. $\mathrm{CO}_{2}$ molecule decomposition is possible through contact with metallic or oxide materials [22-24]. In these processes $\mathrm{CO}_{2}$ plays the role of an oxidant for a substrate. The reaction yield even for the same starting material depends on earlier surface treatment, including the contact of the substrate with a reducing atmosphere [25]. However, many materials in contact with $\mathrm{CO}_{2}$ may exhibit a tendency to form carbonates rather than oxidate and it is necessary to check for the occurrence of sorption or decomposition of gas molecules.

In this work it has been shown that both strontium titanate powders doped with chromium and a mixture of $\mathrm{TiO}_{2}$ with $\mathrm{Ni}$ can be oxidized not only in air but also in carbon dioxide atmosphere. It was found that when both above mentioned atmospheres are used as oxidizing agents and a mixture of $\mathrm{H}_{2}$ with $\mathrm{Ar}$ is applied as a reducing agent, the cyclic and reversible red-ox processes are possible to occur on the investigated powders. The principal aim of the paper is to show a conceptual development of CLC-based processes based on the application of solid oxygen carriers oxidized not only in air but also in $\mathrm{a}_{2}$ atmosphere.

\section{Sample preparation}

The investigated samples were obtained in a solid state reaction process by mixing and subsequent annealing of the pure chemical reagents at $800{ }^{\circ} \mathrm{C}$, in a pure oxygen atmosphere. The substrates of $\mathrm{SrCO}_{3}, \mathrm{TiO}_{2}$ and $\mathrm{Cr}$ were added in mole ratios of 1.00:0.85:0.15 respectively. This procedure resulted in the obtaining of a two-phase material. Following the main $\mathrm{SrTiO}_{3}$ phase the sample consisted of $\mathrm{SrCrO}_{4}$. After treating the sample with a hydrogen atmosphere at the temperature of $800{ }^{\circ} \mathrm{C}$ a one-phase $\mathrm{SrTiO}_{3}$ sample doped with chromium (STO:Cr) with the perovskite structure was obtained. A similar process was applied for the sample of $\left(\mathrm{TiO}_{2}-\mathrm{Ni}\right)$, where both substrates characterized by 1:1 molar ratio were annealed in air conditions at $1000{ }^{\circ} \mathrm{C}$ and next reduced at $900{ }^{\circ} \mathrm{C}$. After the first step the phase composition included $\mathrm{TiO}_{2}, \mathrm{Ni}, \mathrm{NiO}$ and $\mathrm{NiTiO}_{3}$, while after the second step only $\mathrm{TiO}_{2}$ and $\mathrm{Ni}$ were present in the sample.

\section{Measurements techniques}

The thermogravimetry analysis (TGA) measurements were carried out at $800{ }^{\circ} \mathrm{C}$ in an alternating atmosphere, namely, carbon dioxide and reducing atmosphere (argon with an admixture of ca $3 \%$ hydrogen) by means of a STA 409 PC thermal analyser produced by Netzsch. At the same conditions X-ray powder diffraction (XRD) measurements were taken using an X'Pert Pro MPD PANanalitycal difractometer. To enable in-situ XRD investigations, the Anton Paar HTK 2000 high-temperature chamber was adapted to 
experiments in a controlled atmosphere (equipping the gas lines and flow meter). X-ray Photoelectron Spectroscopy (XPS) measurements were performed ex-situ by means of a Physical Electronics PHI 5700 spectrometer with monochromatized $\mathrm{Al} \mathrm{K \alpha}$ radiation. The samples for XPS investigations were prepared according to the same temperature curve and at the same gas atmosphere as in TGA measurements. The TGA measurement was simply stopped at the end of an appropriate stage of sample exposure to air or $\mathrm{CO}_{2}$ conditions and the sample was cooled at the same gas atmosphere as in the testing stage.

\section{Research methodology of oxygen transport capacity of the solid oxides under alternating $\mathrm{CO}_{2}$ and $\mathrm{H}_{2}$ atmospheres}

TGA results presented in Figures 1 and 2 demonstrate the $\mathrm{TiO}_{2}-\mathrm{Ni}$ and STO:Cr sample mass changes during heating at the changing atmospheres, namely $\mathrm{CO}_{2}$ and reducing atmosphere $\left(3 \% \mathrm{H}_{2}\right.$ in $\left.\mathrm{Ar}\right)$, respectively. It is visible that the sample mass decreases under reducing conditions and increases in the presence of $\mathrm{CO}_{2}$. In the case of both samples the process is reversible. The value of changes reaches approximately $4 \%$ for the first sample and $0.7 \%$ for the second. In relation to the CLDR process, an interesting question is whether this process of cyclic mass changes is connected with the sorption of $\mathrm{CO}_{2}$ molecules or with oxidation (possible after prior decomposition of $\mathrm{CO}_{2}$ molecules). It cannot be determined solely on the basis of the TG method. To distinguish whether it is gas sorption or decomposition, the XRD technique was applied.

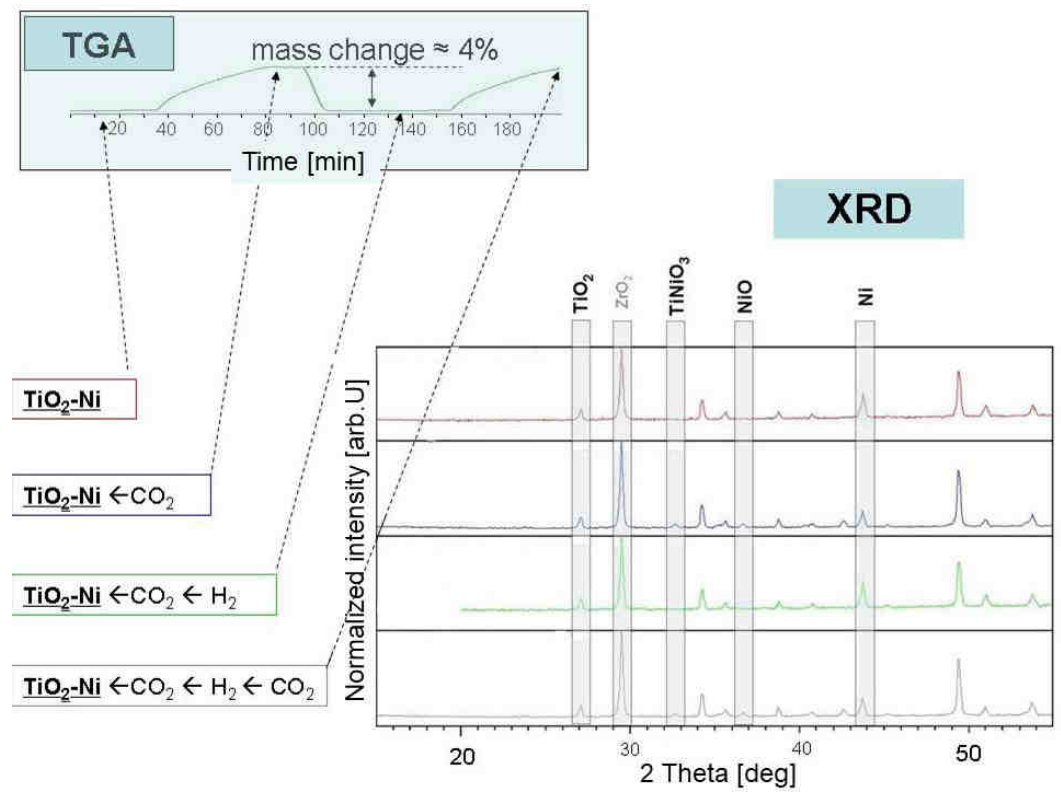

Fig. 1. Mass and phase composition changes of powdered " $\mathrm{TiO}_{2}-\mathrm{Ni}$ " sample upon exposure to a variable atmosphere of $\mathrm{CO}_{2}$ and reduced atmosphere $\left(3 \% \mathrm{H}_{2}\right.$ in $\left.\mathrm{Ar}\right)$ at $900{ }^{\circ} \mathrm{C}$. For the sake of clarity, only the main reflexes of identified phases have been marked. Other peaks also come from the indicated phases $\left(\mathrm{ZrO}_{2}\right.$ peaks originate from the holder) 
The results of atmosphere-dependent XRD measurements in a high-temperature chamber are also presented in Figures 1 and 2 . It is visible that when $\mathrm{TiO}_{2}-\mathrm{Ni}$ powder came in contact with $\mathrm{CO}_{2}$, additional new phases with a higher oxidation state of $\mathrm{Ni}$, namely $\mathrm{NiO}$ and $\mathrm{NiTiO}_{3}$, were formed. However, both phases vanished in contact with the reducing agent and the sample contains only $\mathrm{TiO}_{2}$ and metallic Ni. The process is reversible.

It is worth noting that in the XRD pattern of the sample treated by $\mathrm{CO}_{2}$ atmosphere there are no forms of carbonates. Moreover, in experiments in which the sample was exposed to air instead of $\mathrm{CO}_{2}$, the appearing phases were the same (Table 1). It might be therefore concluded that the $\mathrm{TiO}_{2}-\mathrm{Ni}$ sample could be a solid oxygen carrier capable of oxidizing in both air and $\mathrm{CO}_{2}$ atmospheres. Furthermore, the results of XRD can be used to estimate the maximum efficiency of the process under the assumed conditions of the experiment. We assume that the phenomena occur according to the below reaction, in which the oxidation state of the whole $\mathrm{Ni}$ contained in the sample is increased:

$$
\mathrm{Ni}+\mathrm{TiO}_{2}+\frac{1}{2} \mathrm{O}_{2} \rightarrow \mathrm{NiTiO}_{3} \text { or } \mathrm{Ni}+\mathrm{TiO}_{2}+\mathrm{CO}_{2} \mathrm{CO}_{2} \rightarrow \mathrm{CO}+\frac{1}{2} \mathrm{O}_{2} \rightarrow \mathrm{NiTiO}_{3}+\mathrm{CO}
$$

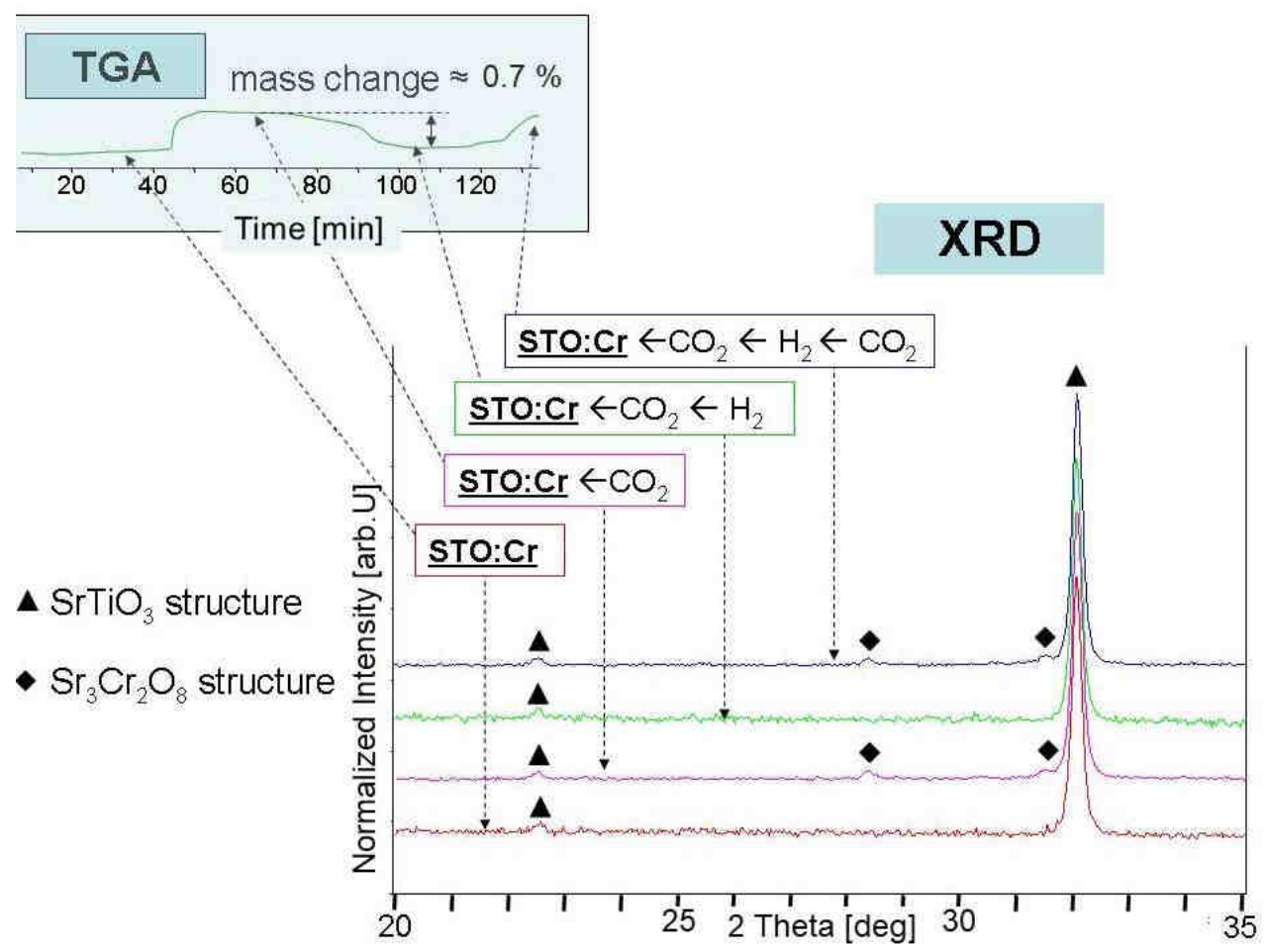

Fig. 2. Mass and phase composition changes of a powdered STO:Cr sample upon exposure to a variable atmosphere of $\mathrm{CO}_{2}$ and reduced atmosphere $\left(3 \% \mathrm{H}_{2}\right.$ in $\left.\mathrm{Ar}\right)$ at $800{ }^{\circ} \mathrm{C}$

Taking into account the molecular weight of the solid substrates and products of the reaction (about 138.6 and 154.6, respectively) a maximum percentage mass change would reach approximately $11.5 \%$ (the weight gain of the sample/initial weight of the sample). 
This information allows determining how much "reserve" is still in the performance of the system and whether it is worth modifying the substrate (for example by additional grinding) or changing the terms of the experiment (for example by changing the process temperature), etc.

Another example is connected with an STO:Cr sample characterized by very low efficiency of oxygen transport ability (Table 1, Fig. 2).

However the results are also presented from a methodological point of view with using an additional XPS study. During the interaction of a powdered STO:Cr sample with $\mathrm{CO}_{2}$, an additional new phase of $\mathrm{Sr}_{3} \mathrm{Cr}_{2} \mathrm{O}_{8}$ was formed. However, after subsequent exposure of the sample to reducing conditions this new phase disappeared. The reflexes from $\mathrm{Sr}_{3} \mathrm{Cr}_{2} \mathrm{O}_{8}$ appear again after another contact of the reduced sample with $\mathrm{CO}_{2}$. It can be therefore concluded that during the alternating contact of the sample with carbon dioxide and hydrogen atmosphere, new $\mathrm{Sr}_{3} \mathrm{Cr}_{2} \mathrm{O}_{8}$ phases were released and dissolved respectively. This might indicate that in reactions of STO:Cr with $\mathrm{CO}_{2}$ at least some of the gas molecules are decomposed and the oxygen released as a result of this decomposition is joined by the solid sample (increasing the oxidation level of $\mathrm{Cr}$ ).

Mass and phase changes revealed in TGA and XRD measurements for $\mathrm{TiO}_{2}$-Ni and $\mathrm{STO}: \mathrm{Cr}$ samples exposed alternately to reducing (ca. $3 \%$ solution of hydrogen in argon) and oxidizing (air or $\mathrm{CO}_{2}$ ) conditions

\begin{tabular}{|c|c|c|c|}
\hline Sample & $\begin{array}{l}\text { Measurement } \\
\text { conditions }\end{array}$ & Phase composition & $\begin{array}{c}\text { Relative } \\
\text { weight change } \\
{[\%]}\end{array}$ \\
\hline \multirow{4}{*}{$\mathrm{TiO}_{2}-\mathrm{Ni}$} & Reduced, $900{ }^{\circ} \mathrm{C}$ & $\mathrm{Ni}, \mathrm{TiO}_{2}$ & \multirow{4}{*}{4.5} \\
\hline & $\mathrm{CO}_{2}, 900^{\circ} \mathrm{C}$ & $\mathrm{Ni}, \mathrm{TiO}_{2}, \mathrm{NiTiO}_{3}, \mathrm{NiO}$ & \\
\hline & Reduced, $900{ }^{\circ} \mathrm{C}$ & $\mathrm{Ni}, \mathrm{TiO}_{2}$ & \\
\hline & $\mathrm{CO}_{2}, 900^{\circ} \mathrm{C}$ & $\mathrm{Ni}, \mathrm{TiO}_{2}, \mathrm{NiTiO}_{3}, \mathrm{NiO}$ & \\
\hline \multirow{4}{*}{$\mathrm{TiO}_{2}-\mathrm{Ni}$} & Reduced, $900{ }^{\circ} \mathrm{C}$ & $\mathrm{Ni}, \mathrm{TiO}_{2}$ & \multirow{4}{*}{9.4} \\
\hline & air, $900{ }^{\circ} \mathrm{C}$ & $\mathrm{Ni}, \mathrm{TiO}_{2}, \mathrm{NiTiO}_{3}, \mathrm{NiO}$ & \\
\hline & Reduced, $900{ }^{\circ} \mathrm{C}$ & $\mathrm{Ni}, \mathrm{TiO}_{2}$ & \\
\hline & air, $900^{\circ} \mathrm{C}$ & $\mathrm{Ni}, \mathrm{TiO}_{2}, \mathrm{NiTiO}_{3}, \mathrm{NiO}$ & \\
\hline \multirow{4}{*}{ STO:Cr } & Reduced, $800{ }^{\circ} \mathrm{C}$ & $\mathrm{SrTiO}_{3}$ & \multirow{4}{*}{0.7} \\
\hline & $\mathrm{CO}_{2}, 800^{\circ} \mathrm{C}$ & $\mathrm{SrTiO}_{3}, \mathrm{Sr}_{3} \mathrm{Cr}_{2} \mathrm{O}_{8}$ & \\
\hline & Reduced, $800{ }^{\circ} \mathrm{C}$ & $\mathrm{SrTiO}_{3}$ & \\
\hline & $\mathrm{CO}_{2}, 800{ }^{\circ} \mathrm{C}$ & $\mathrm{SrTiO}_{3}, \mathrm{Sr}_{3} \mathrm{Cr}_{2} \mathrm{O}_{8}$ & \\
\hline \multirow{4}{*}{ STO:Cr } & Reduced, $800{ }^{\circ} \mathrm{C}$ & $\mathrm{SrTiO}_{3}$ & \multirow{4}{*}{1.4} \\
\hline & air, $800^{\circ} \mathrm{C}$ & $\mathrm{SrTiO}_{3}, \mathrm{SrCrO}_{4}$, u.ph. ${ }^{*}$ & \\
\hline & Reduced, $800^{\circ} \mathrm{C}$ & $\mathrm{SrTiO}_{3}$, u.ph. & \\
\hline & air, $800^{\circ} \mathrm{C}$ & $\mathrm{SrTiO}_{3}, \mathrm{SrCrO}_{4}$, u.ph. & \\
\hline
\end{tabular}

* unidentified phase - clearly visible only one reflex, most probably of $\mathrm{TiO}_{2}$

However, due to small changes in the XRD pattern of the sample under $\mathrm{CO}_{2}$ conditions and various phase formation in $\mathrm{CO}_{2}$ and in air atmospheres (Table 1), a confirmative analysis should be carried out by means of an additional method. For the presented example the decomposition is confirmed by XPS investigations.

In the spectra of $\mathrm{Cr} 2 \mathrm{p}$ (with intensity normalized to the highest signal) presented in Figure 3 one can see two separate states of $\mathrm{Cr} 2 \mathrm{p}$ core level. The position of the $\mathrm{Cr} 2 \mathrm{p}$ spectrum on XPS binding energy scale generally moves towards higher binding energies with an increasing oxidation state of chromium [26, 27]. This fact was additionally confirmed by comparative XPS measurements for the STO:Cr sample after heating in air 
(Fig. 3). Therefore, in the spectra presented in Figure 3 a higher binding energy signal at a range close to $580 \mathrm{eV}$ is connected with a higher oxidation state. Taking into account the higher oxidation state of $\mathrm{Cr}$ and the lack of enhancement of $\mathrm{C} 1 \mathrm{~s}$ spectrum in the binding energy region corresponding to carbonates [28-30] after contact with $\mathrm{CO}_{2}$, it can be stated that the STO:Cr sample was oxidized.

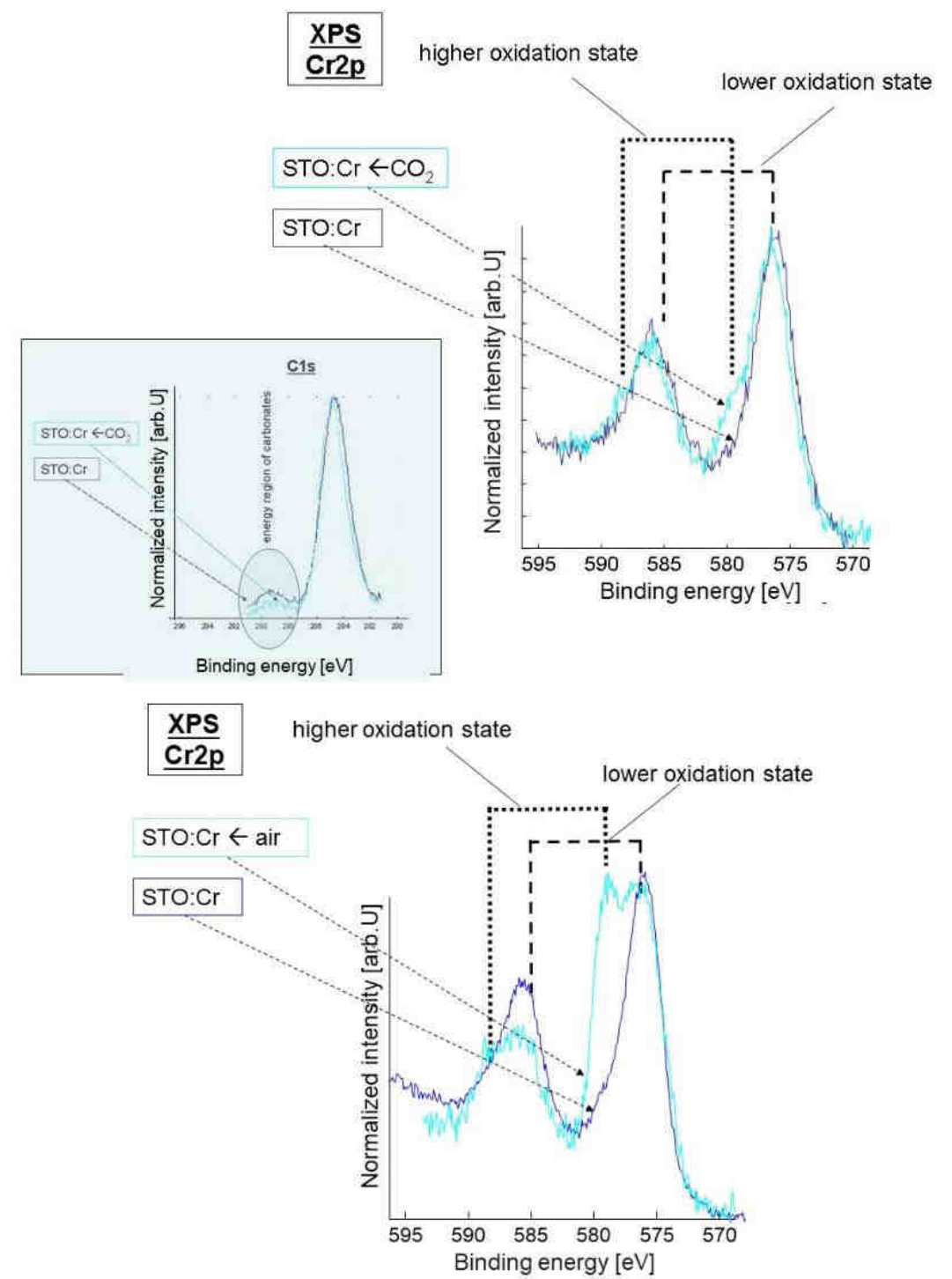

Fig. 3. A comparison between XPS Cr2p spectra of STO:Cr upon exposure to $\mathrm{CO}_{2}$ and air. The inset shows $\mathrm{C} 1 \mathrm{~s}$ spectra before and after the sample exposure to $\mathrm{CO}_{2}$ atmosphere 
TGA and XRD data (Fig. 2) shows that reversibility of the sample oxidation and reduction at appropriate conditions is possible. Thus, it has been shown on the basis of TG, XRD and XPS investigations that there are solid oxygen carriers oxidized in both air and $\mathrm{CO}_{2}$ atmosphere. Moreover, it is important that oxidation in an oxidizing atmosphere and reduction by hydrogen have a reversible character. The cyclic reversibility of the process of oxidation (in both air and $\mathrm{CO}_{2}$ ) and reduction of the investigated powders could be interesting in studies regarding the reduction of energy consumption and $\mathrm{CO}_{2}$ emissions. The results allow a theoretical development of the chemical looping combustion operation or related processes, such as chemical looping dry reforming or chemical looping gasification.

\section{Conceptual modification of CLC and CLDR processes}

For further discussion it is convenient to start with the following remarks. There are oxygen carriers capable of oxidizing not only in air but also in a $\mathrm{CO}_{2}$ atmosphere. The oxidation process in both atmospheres can be reversible for samples reduced in the meantime. In the CLC process run with fuel combustion using oxygen transported by solid carriers the main gaseous product is $\mathrm{CO}_{2}$. These facts indicate that modification of the CLC process could be taken into account, namely, the recirculation of $\mathrm{CO}_{2}$ instead of air in some cycles can be considered (Fig. 4a). Such recycling of gas from the fuel reactor is even more desirable in the CLDR process. However, in this case recycling can be permanent (Fig. 4b). It is important to note that the oxidation of carriers during cycles in a $\mathrm{CO}_{2}$ atmosphere is accompanied by the production of toxic $\mathrm{CO}$. However, due to much higher reactivity of carbon monoxide than carbon dioxide, this monoxide is helpful in the synthesis of useful organic products, for example in Fischer-Tropsch process [31-33]. Then $\mathrm{CO}$ does not have to be emitted into the atmosphere. This remark was added to diagrams in Figure 4a and 4b.

Moreover, the new conceptual proposition for the development of CLC and CLDR processes has been added. The idea is based on the well-known reaction of $\mathrm{CO}$ disproportionation $\left(\mathrm{CO}+\mathrm{CO} \rightarrow \mathrm{CO}_{2}+\mathrm{C}\right)$ and was highlighted in Figure $4 \mathrm{c}$. The " $\mathrm{CO}_{2}$ reactor" presented in Figure $4 \mathrm{c}$ can (but does not have to) be the same reactor as "air reactor" or " $\mathrm{CO}_{2}$ reactor" in the schemes presented in Figures $4 \mathrm{a}$ and $4 \mathrm{~b}$, respectively. The disproportionation reaction is possible when a catalyst of the most frequent transition metal or various compounds thereof is used. It is known that this so-called Boudouard process [34] can be used in the production of morphologically different forms of carbon, such as nanotubes, nanoparticles, encapsulated by carbon nanoparticles of metal, etc. [34, 35]. From the point of view of the discussion presented in this paper, the most important is the fact that during the disproportionation process 2 molecules of $\mathrm{CO}$ give 1 molecule of $\mathrm{CO}_{2}$. One can therefore imagine the following cyclic process. First $\mathrm{CO}_{2}$ oxidizes a solid carrier and causes the emission of $\mathrm{CO}$ (one $\mathrm{CO}_{2}$ molecule is decomposed into one $\mathrm{CO}$ molecule and one oxygen atom, which interact with the sample surface). Then the carrier is reduced by fuel in the CLC or CLDR process and is ready for subsequent decomposition of $\mathrm{CO}_{2}$ molecules. These could be molecules formed after the disproportionation reaction because in the meantime $\mathrm{CO}$ is transformed into any morphological carbon form in the Boudouard reaction and causes $\mathrm{CO}_{2}$ emissions (two molecules of $\mathrm{CO}$ have been "used" to produce one $\mathrm{CO}_{2}$ molecule). 
a)

b)
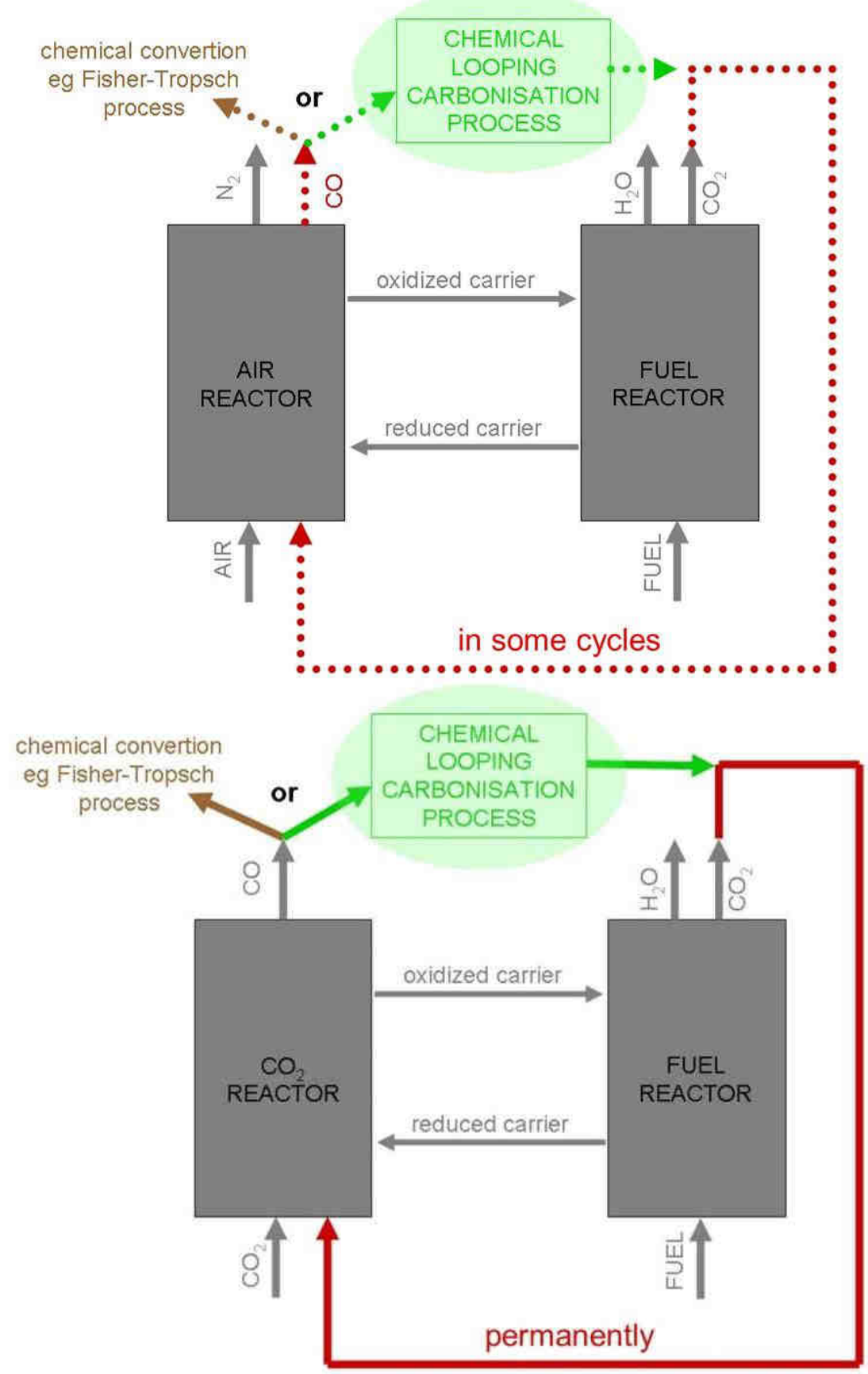
c)

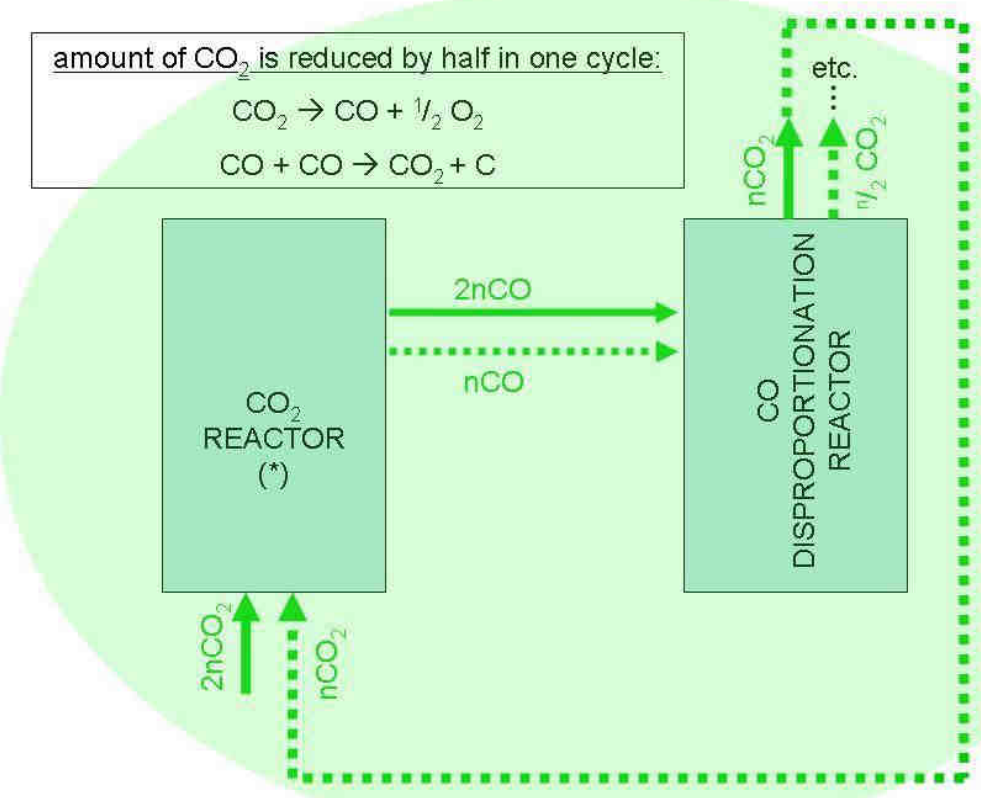

$\left.{ }^{*}\right)$ can be the same reactor as "air reactor" in the CLC or "CO2 reactor" in CLDR processes

Fig. 4. Diagrams of: a) modified process of Chemical Looping Combustion (the part of the diagram in grey colour represents typical CLC process), b) modified process of Chemical Looping Dry Reforming (the part of the diagram in grey colour represents typical CLDR process), c) conceptual process of Chemical Looping Carbonisation

It should be emphasized that in the full cycle $\mathrm{CO}_{2}$ emission is reduced by half. Of course, this applies to molecules involved in the reaction, and assumes $100 \%$ efficiency of the process. It should be added that the presented model is only conceptual and has not been studied in terms of calculations of the process efficiency, the reactor construction requirements or economic calculation. However, it should be noted that the reaction of $\mathrm{CO}$ disproportionation is possible even at a relatively low temperature $\left(300{ }^{\circ} \mathrm{C}\right)$. For example, conducted for this article calculations with the use of the FactSage software (version 6.3) have shown that at this temperature the disproportionation reaction of $\mathrm{CO}$ occurs spontaneously at the presence of a Ni catalyst. This value is a few hundred degrees less than the oxidation temperature of the majority of the most popular oxygen carriers $[2-4,21]$ and also the investigated $\mathrm{Ni}-\mathrm{TiO}_{2}$ carrier. One can imagine that the stream of gaseous products (mainly $\mathrm{CO}$ ) of $\mathrm{CO}_{2}$ contact with the carrier at $900{ }^{\circ} \mathrm{C}$ is forwarded to the disproportionation reactor where without the additional energy inputs for heating the manufacturing of any required forms of carbon is realised. Then the presented idea, based on appropriate materials and construction solutions seems to be feasible. Moreover, combining the chemical looping combustion process (similarly to gasification or reforming) with the process of carbon production in the given morphological variation should require less energy input and cause lower $\mathrm{CO}_{2}$ emissions than in the case of running both processes separately. The combined process can be called Chemical Looping Carbonisation Process. 


\section{Summary and conclusion}

In the manuscript TG, XRD and XPS investigations into changes in powdered $\mathrm{Sr}(\mathrm{Ti}, \mathrm{Cr}) \mathrm{O}_{3}$ and $\mathrm{TiO}_{2}-\mathrm{Ni}$ samples upon alternating contact with air and $\mathrm{H}_{2}$ gaseous solution have been described. Analogous measurements were carried out by replacing the air by the carbon dioxide. It has been demonstrated that cyclic red-ox processes are possible in both cases. The satisfactory level of oxygen transport (almost $10 \%$ in the case of oxidation in air and nearly $5 \%$ in $\mathrm{CO}_{2}$ ) was obtained for $\mathrm{TiO}_{2}-\mathrm{Ni}$ carriers. The possibility of the "looping" process on the same carriers using both $\mathrm{CO}_{2}$ and air atmosphere as an oxidizing agent allows us to enrich the concept of CLC and related processes by proposing a cyclic recirculation of the produced $\mathrm{CO}_{2}$ back to the installation. The oxidizing of solid oxygen carrier in a $\mathrm{CO}_{2}$ atmosphere is accompanied by $\mathrm{CO}$ emission from the plant. This toxic gas could be transformed into a useful product in any chemical process, like the production of fuels in Fisher-Tropsch synthesis. However, it is also possible to combine the chemical looping combustion/gasification/reforming process with carbon (with an appropriate morphological form) manufacturing in the cyclic $\mathrm{CO}$ disproportionation process. This could also lead to a reduction in energy input and lower $\mathrm{CO}_{2}$ emissions to the environment.

\section{Acknowledgments}

One of us (B.P.) thanks Professor K. Szot for drawing attention to the subject of $\mathrm{CO}_{2}$ decomposition over perovskite structure materials.

\section{References}

[1] Kyoto Protocol. United Framework Convention on Climate Change. United Nations, Kyoto 1997. Available from: https://unfccc.int/resource/docs/convkp/kpeng.pdf.

[2] Ksepko E, Łabojko G. J Therm Anal Calorim. 2014;117:151-62. DOI: 10.1007/s10973-014-3674-x.

[3] Ksepko E, Klimontko J, Kwiecinska A. J Therm Anal Calorim. 2019;138:4247-60. DOI: 10.1007/s10973-019-08214-8.

[4] Azimi G, Mattisson T, Leion H, Ryden M, Lyngfelt A. Int J Greenh. 2015;34:12-24. DOI: 10.1016/j.ijggc.2014.12.022.

[5] Dennis JS, Müller CR, Scott SA. Fuel. 2010;89:2353-64. DOI: 10.1016/j.fuel.2010.01.037.

[6] Adánez J, Abad A, Mendiara T, Gayán P, De Diego LF, García-Labiano F. Prog Energy Combust. 2018; 65:6-66. DOI: 10.1016/j.pecs.2017.07.005.

[7] Ksepko E. Int J Hydrogen Energy. 2018;43(20):9622-34. DOI: 10.1016/j.ijhydene.2018.04.046.

[8] Dai Z, Viswanathan H, Xiao T, Middleton R, Pan F, Ampomah W, et al. Energy Procedia. 2017;114:6957-67. DOI: 10.1016/j.egypro.2017.08.034.

[9] Wang X, van’t Veld K, Marcy P, Huzurbazar S, Alvarado V. Appl Energy. 2018;222:132-47. DOI:10.1016/j.apenergy.2018.03.166.

[10] Shabani B, Vilcáez J. Comput Geosci. 2018;111:58-66. DOI: 10.1016/j.cageo.2017.10.012.

[11] Ghanbari S, Mackay EJ, Heinemann N, Alcalde J, James A, Allen MJ. Appl Energy. 2020;278:115634. DOI: 10.1016/j.apenergy.2020.115634.

[12] Alcántar-Vázquez B, Duan Y, Pfeiffer H. Ind Eng Chem Res. 2016;55(37):9880-6. DOI: 10.1021/acs.iecr.6b02257.

[13] Kemache N, Pasquier LC, Cecchi E, Mouedhen I, Blais JF, Mercier G. Fuel Process Technol. 2017;166:209-16. DOI: 10.1016/j.fuproc.2017.06.005.

[14] Baena-Moreno FM, Rodríguez-Galán M, Vega F, Alonso-Fariñas B, Vilches Arenas LF, Navarrete B. Energy Source Part A. 2019;41(12):1403-33. DOI: 10.1080/15567036.2018.1548518

[15] Amari D, Lopez Cuesta JM, Nguyen NP, Jerrentrup R, Ginoux JL. J Thermal Analysis. 1992;38:1005-15. DOI: $10.1007 / \mathrm{BF} 01979434$.

[16] Martavaltzi CS, Lemonidou AA. Micropor Mesopor Mat. 2008;110:119-27. DOI: 10.1016/j.micromeso.2007.10.006. 
[17] Khedr MH, Bahgat M, Nasr MI, Sedeek EK. Colloids Surf A Physicochem Eng Asp. 2007;302:517-24. DOI: 10.1016/j.colsurfa.2007.03.024.

[18] Matsumoto H, Tanabe S, Okitsu K, Hayashi Y, Suib SL. Bull Chem Soc Jpn. 1999;72:2567-71. DOI: 10.1246/bcsj.72.2567.

[19] Lin KS, Adhikari AK, Tsai ZY, Chen YP, Chien TT, Tsai HB. Catal Today. 2011;174:88-96. DOI: 10.1016/j.cattod.2011.02.013.

[20] Zhang K, Zhang G, Liu X, Phan AN, Luo K. Ind Eng Chem Res. 2017;56:3204-16. DOI: 10.1021/acs.iecr.6b04570.

[21] Najera M, Solunke R, Gardnem T, Veser G. Chem Eng Res Des. 2011;89:1533-43. DOI: 10.1016/j.cherd.2010.12.017.

[22] Szot K, Keppels J, Speer W, Besocke K, Teske M, Eberhardt W. Surf Sci. 1993;280:179-84. DOI: 10.1016/0039-6028(93)90366-R.

[23] Wu XY, Ghoniem AF. Prog Energy Combust Sci. 2019;74:1-30. DOI: 10.1016/j.pecs.2019.04.003.

[24] Dharanipragada NA, Meledina M, Galvita VV, Poelman H, Turner S, Van Tendeloo G, et al. Ind Eng Chem Res. 2016;55:5911-22. DOI: 10.1021/acs.iecr.6b00963.

[25] Pena MA, Fierro JLG. Chem Rev. 2001;101:1981-2017. DOI: 10.1021/cr980129f.

[26] Liu X, Su W, Lu Z, Liu J, Pei L, Liu W, et al. J Alloys Compd. 2000;305:21-3. DOI: 10.1016/S0925-8388(00)00735-0.

[27] Biesinger MC, Brown C, Mycroft JR, Davidson RD, McIntyre NS. Surf Interface Anal. 2004;36:1550-63. DOI: $10.1002 /$ sia. 1983.

[28] Handbook of X-Ray Photoelectron Spectroscopy. Eden Prairie Minnesota: Physical Electronics Inc; 1995. ISBN: 096481241X.

[29] Chen G, Liu H, He Y, Zhang L, Asghar MI, Geng S, et al. J Mater Chem A. 2019;7:9638-45. DOI: 10.1039/C9TA00499H.

[30] Wala T, Psiuk B, Kubacki J, Stec K, Podwórny J. Ceram Int. 2014;40:5129-36. DOI: 10.1016/j.ceramint.2013.10.036.

[31] Tsubaki N, Fujimoto K. Fuel Process Technol. 2000;62:173-86. DOI: 10.1016/S0378-3820(99)00122-8.

[32] Chen PP, Liu JX, Li WX. ACS Catal. 2019;9:8093-103. DOI: 10.1021/acscatal.9b00649.

[33] Göbel C, Schmidt S, Froese C, Fu Q, Chen YT, Pan Q, et al. J Catal. 2020;383:33-41. DOI: 10.1016/j.jcat.2020.01.004.

[34] Nikolaev P, Bronikowski MJ, Kelley Bradley R, Rohmund F, Colbert DT, Smith KA, et al. Chem Phys Lett. 1999;313:91-7. DOI: 10.1016/S0009-2614(99)01029-5.

[35] Nolan PE, Butler AH, Lynch DG. Method for producing encapsulated nanoparticles and carbon nanotubes using catalytic disproportionation of carbon monoxide and the nanoecapsulated and nanotubes formed thereby. 1999. United States patent 5,965,267. Available from: https://www.google.com/patents/US5965267. 